\title{
Avaliação da eficiência de três diferentes configurações de reatores anaeróbios para maior retenção de sólidos e fins de reuso
}

\author{
Evaluation of the efficiency of three different configurations of \\ anaerobic reactors for greater retention of solids and reuse purposes
}

\author{
Bruna Gomes de Lima \\ brunaaifce@hotmail.com \\ IFCE, campus Limoeiro do \\ Norte.
}

Francisca Socorro Peixoto socorropeixoto2009@ hotmail.com IFCE, campus Limoeiro do Norte.

\section{Heraldo Antunes Silva Filho heraldo@ifce.com.br IFCE, campus Limoeiro do Norte.}

\section{Elivânia Vasconcelos Moraes dos Santos elivania@ifce.com.br IFCE, campus Limoeiro do Norte.}

\begin{abstract}
Resumo
O tratamento de esgotos em pequenas comunidades integrantes do saneamento rural ou sistemas unifamiliares deve garantir qualidade do efluente tratado e apresentar disposição final segura. Neste trabalho, propôs-se a confecção de dois reatores anaeróbios de manta de lodo (UASB), previstos para o tratamento de pequenas e médias vazões, sendo um deles o reator UASB "Y", desenvolvido por van Haandel e Lettinga (1994), e o outro, semelhante ao reator "Y", com uma proposição de maior acúmulo de sólidos: o reator "K". Buscou-se identificar o sistema mais acessível em relação ao custobenefício e eficiência na remoção de sólidos e matéria orgânica. Utilizou-se um decanto-digestor como "controle", sendo este o mais utilizado no uso unifamiliar. O reator "K" apresentou maior eficiência do que o reator "Y" (acréscimo aproximadamente de 10\% aos percentuais de remoção); e ambos, maiores vantagens do que o decanto-digestor. Os sistemas em estudo mostraram potencial ao reuso indireto não potável para fins menos nobres.
\end{abstract}

Palavras-chave: Tratamento. UASB. Reuso.

\begin{abstract}
The sewage treatment in small communities, members of rural sanitation systems or single-family, must ensure quality of treated effluent and provide safe disposal. This paper has proposed to construct two anaerobic sludge blanket (UASB) provided for the treatment of small and medium flows, one of the UASB reactor "Y" developed by van Haandel and Lettinga (1994) and similar to other reactor "Y", by proposing a greater accumulation of solids: reactor " $\mathrm{K}$ ". We tried to identify the system more accessible to the cost-effectiveness and efficiency in the removal of solids and organic matter. We used a decanter-digester as "control", which is the most widely used in single-family use. The reactor "K" had a higher efficiency than the reactor "Y" (increase of approximately 10\% for percentage of removal) and both the biggest advantages that the decanter-digester. The systems under study showed no potential for indirect potable reuse for less noble purposes.
\end{abstract}

Keywords: Treatment. UASB. Reuse.

\section{Introdução}

O Brasil possui a quinta maior população do mundo, tendo atingido, em novembro de 2010, 190 milhões de habitantes, de acordo com o Instituto Brasileiro de Geografia e Estatística (IBGE), o que traduz um crescimento de 21 milhões de pessoas, comparando-se à população recenseada no ano 2000.

Destaca-se, entretanto, que, apesar de tal incremento populacional ser bastante expressivo e demandar minuciosos critérios de projeção populacional, organizacional e de zoneamento, esse acréscimo vem sendo pautado na falta de planejamento e no descaso com as questões ambientais locais e mundiais. Tal afirmativa pode ser confirmada com base em diferentes perspectivas, contudo, ao se considerar sobretudo aspectos relativos ao saneamento ambiental, torna-se possível constatar uma pequena abrangência desses serviços quando oferecidos nas grandes regiões brasileiras, situação que reflete 
negativamente na qualidade de vida da população deficitária dos serviços.

Dados mais recentes do IBGE (2010) indicam que, no Brasil, apenas 29\% dos municípios coletam e tratam seus esgotos, sendo o restante, $71 \%$, destinado inadequadamente ao solo ou a corpos hídricos circunvizinhos, comprometendo os recursos naturais integrantes da bacia hidrográfica e podendo, inclusive, extrapolar limites de sobrecargas e capacidade de autodepuração.

Na região Nordeste, o cenário não difere do nacional, onde apenas 19\% dos municípios coletam e tratam seus esgotos (IBGE, 2011). Ressalta-se, ainda, que o tratamento considerado na estatística do IBGE não atribui qual tipo é adotado nem se é adequado aos padrões nacionais e locais de lançamento de águas residuárias, gerando, assim, um cenário de fragilidade ambiental bastante preocupante e requerente de soluções significativas a curto, médio e longo prazo.

A água, após ser utilizada pela população, tem como destino final o retorno ao meio ambiente (mesmo depois do reuso) e, quando não tratada adequadamente, pode reduzir a qualidade de rios e mananciais receptores (principalmente os lênticos), provocando desequilíbrios nos ecossistemas ali presentes.

Para a adequada minimização dessa problemática, o reuso apresenta-se como solução viável, pois pode trazer benefícios tanto econômicos quanto ambientais, diminuir o consumo e desperdício da água potável, além de evitar a contaminação do solo, caso esses esgotos sejam submetidos a um tratamento adequado (Metcalf; Eddy, 2003).

Os decanto-digestores, ou tanques sépticos, são uma das alternativas mais antigas de tratamento de esgotos. Segundo Chernicharo (2007), esse tanque é uma unidade in loco que desempenha diversas funções, como a sedimentação e a remoção de materiais flutuantes, além de funcionar como digestor de baixa carga, que ainda é muito utilizado para o tratamento de esgotos de pequenas áreas, como é o caso de domicílios que não possuem rede coletora.

Contudo, ainda de acordo com Chernicharo (2007), outros sistemas anaeróbios de tratamento de esgotos, conhecidos por reatores de alta taxa, desempenham, de maneira mais eficiente, a função de remoção de poluentes como matéria orgânica e material em suspensão, devido à maior retenção de sólidos (biomassa ativa).

Exemplos típicos de reatores de alta taxa são os reatores de manta de lodo e fluxo ascendente (UASB), que foram e continuam sendo amplamente estudados e aplicados ao tratamento de esgotos, com destaque em situações nas quais os recursos financeiros devem ser reduzidos e a mão de obra operacional, simplificada.

Segundo van Haandel e Marais (1999), o reator UASB compreende um sistema bastante simples, que remove parte do material biodegradável e refratário do afluente. Tendo em vista o uso desses sistemas, alguns estudos buscaram demonstrar que a substituição de decanto-digestores por reatores UASB adaptados a receber pequenas vazões como contribuição diária de esgotos era uma decisão coerente e viável, tendo como principal discurso que a configuração básica dos reatores UASB prevê maior contato do afluente com o lodo, proporcionando melhores condições para a atividade microbiana e, consequentemente, melhor remoção de matéria orgânica. Destaca-se, ainda, que a escolha desse tipo de sistema para uso unifamiliar pode ser adequada, visto que a produção de metano não é considerada relevante e, portanto, não oferece riscos de explosões ou danos ambientais (Coelho et al., 2001; 2002; 2003; Andrade Neto et al., 2002).

O reator anaeróbio em forma de "Y" foi proposto por Van Haandel e Lettinga (1994) como alternativa ao reator de manta de lodo e fluxo ascendente já amplamente difundido e teve uma boa aceitação tanto por parte da comunidade acadêmica quanto por empresas e construtoras de saneamento, visto que seu uso mostrou-se bastante significativo quando utilizado em pequenas comunidades, condomínios, instituições com contribuições de vazões variando entre baixas e médias, comunidades rurais e uso unifamiliar (Van Haandel et al., 1999).

Esta pesquisa foi desenvolvida no intuito de sugestionar, de forma racional, em termos de projeto e aplicabilidade social, um sistema anaeróbio para uso semelhante ao proposto por Van Haandel e Lettinga, viável em termos econômicos, ambientais e em aspectos de simplificação operacional desde a sua instalação.

Nessa perspectiva, foi incrementada à determinação da relação de custo-benefício entre sistemas unifamiliares, como o reator UASB "Y" e o decanto-digestor, uma nova unidade concorrente (reator "K"), buscando-se melhorar o sistema "Y" na remoção de sólidos e matéria orgânica.

Visou-se, ainda, o estudo da possibilidade de reaproveitamento dos efluentes tratados nas próprias comunidades, instituições e residências que fizessem uso do tratamento, culminando no estudo preliminar da aplicação do reuso do esgoto tratado para fins não potáveis, de forma a minimizar possíveis danos ao meio ambiente, além de garantir redução de custos e demanda por água de boa qualidade para fins menos nobres. 


\section{Metodologia}

Os experimentos que compuseram esta pesquisa foram desenvolvidos no Laboratório de Controle Ambiental (LCA) do Instituto Federal de Educação, Ciência e Tecnologia do Ceará, campus Limoeiro do Norte (IFCE-LN), e os sistemas de tratamento em escala experimental testados foram montados e operados no Centro Experimental de Tratamento de Esgotos do campus (CETE).

O esgoto afluente aos sistemas de tratamento operados era oriundo dos banheiros e da cantina das instalações do IFCE-LN, tendo características predominantemente domésticas e vazão de entrada aos reatores variando entre $0,32 \mathrm{~m}^{3} / \mathrm{d}$ (reator "Y), $0,65 \mathrm{~m}^{3} / \mathrm{d}$ (reator " $\mathrm{K}$ ") e $1 \mathrm{~m}^{3} / \mathrm{d}$ (decanto-digestor).

Os esgotos gerados nos laboratórios e demais unidades da instituição foram submetidos à etapa de caracterização físico-química e testes de tratabilidade e biodegradabilidade. Esse tipo de esgoto não foi foco de estudo neste trabalho, devido aos resultados dos testes terem apresentado uma relação DQO/DBO acima de 3,5, o que, de acordo com Von Sperling (2011), é inapropriado ao tratamento biológico.

A pesquisa foi desenvolvida em três etapas principais: (1) montagem e operação dos reatores experimentais "Y", "K" e decanto-digestor, além do acompanhamento da eficiência na remoção de demanda química de oxigênio (DQO) e de sólidos; (2) análise de custo-benefício do projeto de reuso para os esgotos do IFCE-LN; e (3) estudo preliminar da viabilidade de reuso direto não potável na instituição.

\subsection{Montagem, Operação e Eficiência dos Reatores}

Para o desenvolvimento desta pesquisa, buscou-se a identificação do sistema de tratamento mais econômico, tanto em fase de projeto quanto em fase operacional, além de etapas de manutenção. A eficiência na remoção dos principais poluentes previstos na legislação brasileira também foi especialmente considerada, além da capacidade de produção de água de reuso.

Para tanto, propôs-se a confecção de dois reatores do tipo Upflow Anaerobic Sludge Blanket (UASB), com configurações previstas para o tratamento de pequenas e médias vazões, a exemplo de contribuições unifamiliares, pequenas e médias instituições de ensino, pequenos bairros, comunidades rurais, dentre outros.

Uma delas, amplamente difundida no país (reator UASB em forma de "Y"), foi desenvolvida e proposta por Van Haandel e Lettinga (1994). A outra configuração, de aspectos operacionais semelhantes ao reator "Y", apresentava uma proposição de maior acúmulo de sólidos: um reator em forma de "K".

Um decanto-digestor (pré-fabricado, isto é, não confeccionado na pesquisa) foi utilizado como "reator controle", para que pudesse ser realizada uma comparação mais direcionada da qualidade de projeto, operacional e do atendimento aos requisitos ambientais citados e definidos em legislação vigente (Resolução do Conselho Nacional de Meio Ambiente - CONAMA n 357 e n ${ }^{\circ} 430$, e Portaria da Superintendência de Meio Ambiente do Ceará - SEMACE n ${ }^{154}$ ).

Na Figura 1, mostra-se o decanto-digestor que foi adquirido em fibra de vidro e instalado no Centro Experimental de Tratamento de Esgotos (CETE) do IFCE-LN. Esse sistema apresentava volume total de 1,5 $\mathrm{m}^{3}$ e tratava uma vazão máxima de $1 \mathrm{~m}^{3} / \mathrm{d}$. Destaca-se que, apesar de apresentar dimensões e condições operacionais diferenciadas dos reatores UASB, foram realizadas estimativas proporcionais para adequação aos testes, o que de fato, por meio de comparações estatísticas, mostrou-se adequado.

A alimentação desse sistema era feita através de um motor responsável por encaminhar os esgotos coletados no tanque de armazenamento e distribuí-los de forma constante. Um inversor de frequência controlava a rotação do motor, tendo sido possível, assim, estabelecer diferentes vazões e tempos de detenção hidráulica em função dos objetivos da pesquisa. 

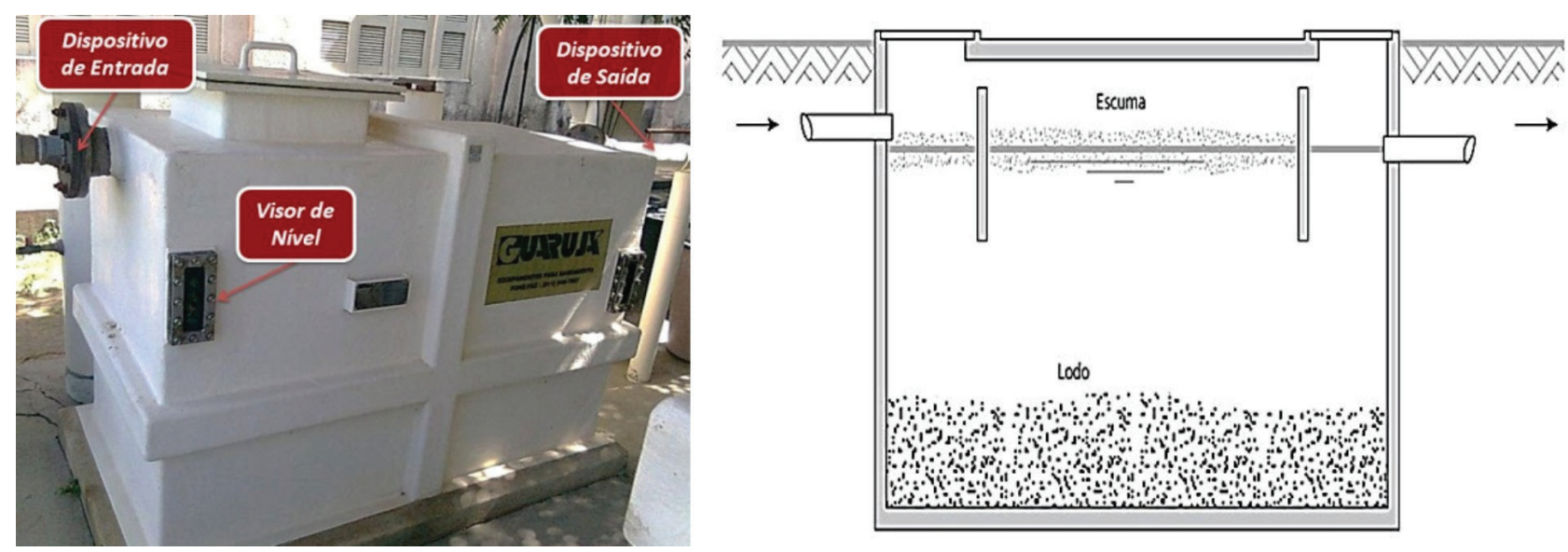

Figura 1: Decanto-digestor de câmara única em fibra de vidro (vista da esquerda) e esquema do detalhamento interno corte (vista da direita).

O segundo reator utilizado na pesquisa, representado na Figura 2, apresentava formato de "Y" e foi confeccionado em PVC, com 2,17 m de altura, diâmetro de $100 \mathrm{~mm}$, tendo um cap acoplado no fundo e sua parte superior aberta para liberação do gás produzido. Segundo Chernicharo (2007), a estabilização da matéria orgânica ocorre em todas as zonas de reação (leito e manta de lodo) do reator de manta de lodo e a mistura ocorre através das bolhas de gás e pelo fluxo do esgoto. Esse sistema produz biomassa de elevada atividade e, na parte superior de sua estrutura, há o separador dos gases e sólidos. Em função do exposto, na parte superior, foi anexado um sistema de defletor de fases na forma de "Y", que funcionava como um decantador externo, com aproximadamente $0,85 \mathrm{~m}$ e um ângulo de $45^{\circ}$ ao eixo da vertical. Ao todo, esse reator apresentava $22 \mathrm{~L}$, sendo destes, apenas $20 \mathrm{~L}$ úteis.

Já o terceiro reator, no formato de "K" (Figura 3), foi montado em PVC, com dois defletores, no intuito de se intensificar a quantidade de retenção dos sólidos. Apresentava volume total de $42 \mathrm{~L}$, dos quais apenas 40 eram úteis.

Esses dois reatores foram operados com um tempo de detenção hidráulica (TDH) de 15 horas. A alimentação dos sistemas UASB era realizada diariamente, de forma ascendente, através de um dispositivo acoplado paralelamente ao reator e com mesma altura, com afluente tipicamente doméstico gerado no campus, através de bombeamento (bomba dosadora), facilitando assim o equilíbrio hidráulico e evitando transbordo pela saída ou pela abertura da liberação dos gases.

Uma bomba dosadora ficou responsável pela manutenção do fluxo contínuo. Ao longo de suas alturas, foram dispostos pontos de coleta, para que fosse possível analisar o perfil do desempenho do reator em diferentes seções, além de operacionalizar possíveis manutenções.

Para a avaliação do desempenho dos sistemas operados, semanalmente, as amostras eram coletadas do tanque de armazenamento (esgoto bruto) e da saída dos reatores (efluentes tratados), sendo, então, realizadas análises laboratoriais, que consistiram na determinação de parâmetros indicativos da eficiência dos sistemas (Tabela 1).

Concomitante à montagem dos reatores, foi realizado um diagnóstico qualitativo e quantitativo dos esgotos gerados no campus. Identificou-se que as diferentes instalações hidrosanitárias de banheiros e cantina não se misturavam com as vazões oriundas dos laboratórios. Tal fator possibilitou uma caracterização específica dos esgotos tipicamente domésticos, que foram objeto de estudo desta pesquisa. 


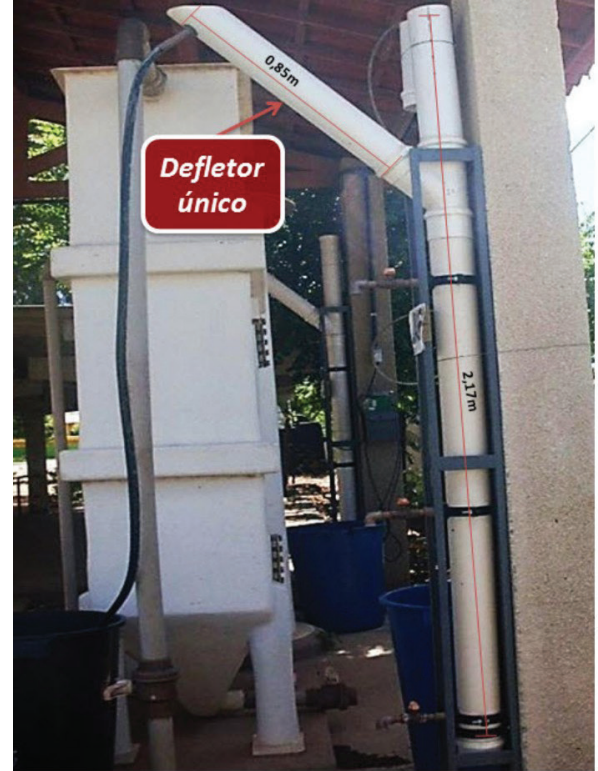

Figura 2: Reator UASB "Y” em PVC com defletor único

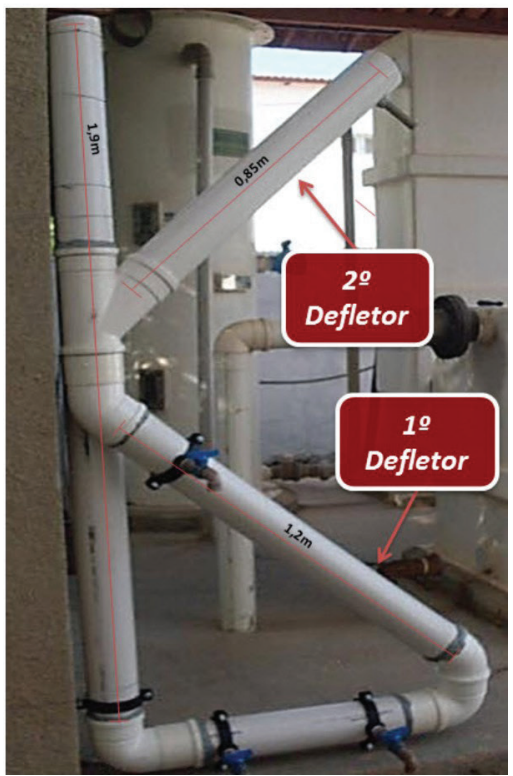

Figura 3: Reator UASB “K”em PVC com dois defletores

Tabela 1: Variáveis analisadas durante o período operacional dos sistemas e suas respectivas metodologias analíticas

\begin{tabular}{|c|c|c|c|}
\hline Variáveis & Unidade & Métodos analíticos & Referências \\
\hline Alcalinidade Total & $\mathrm{mgCaCO}_{3} / \mathrm{L}$ & Kap & Buchauer (1998) \\
\hline Alcalinidade $\mathrm{HCO}_{3}$ & $\mathrm{mgCaCO}_{3}^{3} / \mathrm{L}$ & Kap & Buchauer (1998) \\
\hline Alcalinidade $\mathrm{AGV}^{3}$ & $\mathrm{mgCaCO}_{3}^{3} / \mathrm{L}$ & Kap & Buchauer (1998) \\
\hline $\mathrm{pH}$ & $-{ }^{3}$ & Potenciométrico & Apha et al. (2005) \\
\hline Turbidez & UNT & Turbidimétrico & Apha et al. (2005) \\
\hline Sólidos Sedimentáveis & $\mathrm{mL} / \mathrm{L}$ & Cone Imhof & Apha et al. (2005) \\
\hline Temperatura & ${ }^{\circ} \mathrm{C}$ & Eletrométrico & Apha et al. (2005) \\
\hline Condutividade & $\mu \mathrm{S} / \mathrm{cm}$ & Colorimétrico & Apha et al. (2005) \\
\hline DQO Bruta & $\mathrm{mgDQO} / \mathrm{L}$ & Colorimétrico & Apha et al. (2005) \\
\hline SST & $\mathrm{mg} / \mathrm{L}$ & Gravimétrico & Apha et al. (2005) \\
\hline SSV & $\mathrm{mg} / \mathrm{L}$ & Gravimétrico & Apha et al. (2005) \\
\hline Nitrogênio Amoniacal & $\mathrm{mgN} / \mathrm{L}$ & Semimicro Kjeldahl & Apha et al. (2005) \\
\hline Fósforo Total & $\mathrm{mg} \mathrm{PO}_{4}^{2-/ L}$ & Ácido Ascórbico & Apha et al. (2005) \\
\hline Coliformes Termotolerantes & $\mathrm{NMP} / 100 \mathrm{~mL}$ & Tubos Múltiplos & Apha et al. (2005) \\
\hline Ovos de Helmintos & ovos/L & Bailenger Modificado & Ayres \& Mara (1996) \\
\hline
\end{tabular}

$\mathrm{AGV}=$ ácidos graxos voláteis; $\mathrm{pH}=$ potencial hidrogeniônico; $\mathrm{SST}=$ sólidos suspensos totais; $\mathrm{SSV}=$ sólidos suspensos voláteis.

\subsection{Análise de Custo-Benefício e Estudo da Viabilidade de Reuso}

Para o estudo da relação de custo-benefício dos sistemas avaliados, foi realizada uma análise preliminar referente aos reatores operados, considerando alguns materiais disponíveis à utilização na confecção, tipos de mecanização possivelmente envolvidos, montagem e instalação dos sistemas como um todo, aspectos de manutenção e disposição final de lodo e dos efluentes líquidos tratados.

Existem diversas possibilidades de se confeccionar cada tipo de reator testado. Nesse sentido, foi feito um levantamento dos materiais utilizados mais comuns, considerando os constituintes específicos em cada configuração para identificar qual dos modelos seria o menos oneroso e também o mais eficiente. Destaca-se que, de um modo geral, não se deve priorizar a eficiência, e sim, seu custo; além disso, os sistemas propostos nesta pesquisa visam ao atendimento de pequenas comunidades que, na maioria das vezes, não têm condições de fazer um investimento maior para tal fim. 
Na Tabela 3, estão apresentadas sugestões consideradas mais relevantes ao se identificar os fatores anteriormente citados. Dessa forma, pôde-se agrupar um conjunto de informações constituintes extremamente definitivas na análise econômica, o que facilitaria a opção por um ou outro sistema de tratamento estudado.

Tabela 3: Aspectos avaliados e comparados de acordo com os sistemas operados.

\begin{tabular}{lccc}
\hline Material Utilizado & Mecanização & Montagem / Instalação & Manutenção / Disposição Final \\
\hline PVC & Gravidade & In Loco & Limpa Fossa + Corpo Hídrico Receptor \\
Polipropileno & Bombeamento Simples & Pré-moldado & Limpa Fossa + Valas de Infiltração \\
Fibra de Vidro & Conjunto Motor-Bomba & Pré-fabricado & Limpa Fossa + Sumidouro \\
\hline
\end{tabular}

Após a análise prévia dos aspectos gerais envolvidos aos custos, foram compilados e tabulados os aspectos financeiros e, em seguida, confrontados com os resultados de desempenho (obtidos a partir de análises laboratoriais), finalizando em geração de relatórios.

Uma última avaliação foi realizada, tendo como base aspectos relativos ao reuso da água residuária tratada no IFCE-LN (incluindo tipo e aplicações), focando-se em uma previsão de viabilidade do potencial de reutilização dessas águas previamente tratadas por vias anaeróbias (Metcalf; Eddy, 2003). Destaca-se que a estimativa foi formulada de acordo com a legislação vigente e, na falta de detalhes mais específicos, considerou-se como referência as diretrizes da Organização Mundial de Saúde (OMS).

\section{Resultados e Discussão}

Os resultados obtidos a partir da etapa de caracterização física, química e microbiológica do esgoto estudado encontram-se na Tabela 4. Esses dados foram tratados a partir de estatística básica, de forma a serem obtidos os valores de média dos parâmetros considerados relevantes ao prévio conhecimento do esgoto.

Tabela 4: Resultados obtidos para os parâmetros de caracterização da água residuária estudada.

\begin{tabular}{ccccccc}
\hline $\boldsymbol{n}$ (amostras) & Parâmetros & Média & Desvio Padrão & CV (\%) & Máximo & Mínimo \\
\hline 16 & Turbidez (UNT) & 107 & 47 & 43,7 & 211 & 24 \\
16 & Sólidos Sedimentáveis (mLSS/L) & 1,0 & 0,8 & 83,1 & 4 & 0 \\
16 & Sólidos Suspensos Totais (mgSST/L) & 179 & 122 & 68 & 495 & 38 \\
16 & Sólidos Suspensos Voláteis (mgSSV/L) & 90 & 56 & 62 & 198 & 22 \\
16 & Sólidos Suspensos Fixos (mgSSF/L) & 89 & 79 & 88,6 & 297 & 4 \\
16 & DQO bruta (mg/L) & 283 & 133 & 47 & 532 & 89 \\
16 & Nitrogênio Amoniacal (mgN/L) & 62 & 48 & 76,5 & 166 & 8 \\
16 & Fósforo Total (mg/L) & 12 & 14 & 113,5 & 59 & 1 \\
16 & CTT (NMP/100 mL) & $2,6^{*} 10^{7}$ & $5,1 * 10^{7}$ & 197,6 & $1,8^{*} 10^{8}$ & $1,2^{*} 10^{6}$ \\
6 & Ovos de Helmintos (ovos/L) & 136 & 78 & 57,6 & 255 & 54 \\
\hline
\end{tabular}

Analisando os parâmetros individualmente, nota-se uma tendência à grande variação nos valores afluentes, haja vista que praticamente todos os coeficientes de variação ultrapassam o valor de $40 \%$ (indicando grande variabilidade dos dados). Esse fator pode ser confirmado devido à origem da contribuição da água residuária em questão, sendo considerada uma população volátil (alunos) bem maior do que a população fixa (servidores). Apesar dessa consideração, os valores encontrados aproximam-se dos valores referenciados na literatura, que direcionam para um esgoto predominantemente doméstico, principalmente nos valores de DQO, CTT, nitrogênio amoniacal e fósforo (Von Sperling, 2011; Jordão e Pessoa, 2011).

Após a estabilização do sistema no regime estacionário, caracterizada através da produção e consumo de ácidos graxos voláteis, determinada pela alcalinidade por AGV (aferição indireta da produção de metano), partiu-se para as análises de desempenho dos três sistemas em relação à remoção de DQO bruta, ovos de helmintos e retenção de sólidos. Os demais parâmetros não foram priorizados, pois as tecnologias anaeróbias testadas não são adequadas para a remoção de tais constituintes (nitrogênio, fósforo, CTT), sendo a frequência de análise reduzida a esses parâmetros. 
Observando-se a Figura 4, é possível perceber uma variação considerável nos dados de entrada de DQO. Atribui-se a esse fato as especificidades características do histograma de geração de esgotos da instituição, contudo, os percentuais de remoção mantiveram-se satisfatoriamente em uma faixa constante.

Dessa forma, as Figuras 4 e 5 apresentam, respectivamente, a remoção de DQO em mg/L nos três reatores estudados (decanto digestor, UASB Y e UASB K) e a remoção em dados percentuais. A remoção percentual média encontrada foi de $51 \%$ para o decanto digestor, $60 \%$ para o UASB Y e $68 \%$ para o UASB K, evidenciando uma tendência em maior eficiência para os dois reatores UASB, com destaque para o UASB K (desempenho médio 8\% maior que o UASB Y e $17 \%$ maior que o decanto digestor).

Aos baixos percentuais máximos obtidos na remoção de matéria orgânica, sobretudo em relação aos reatores UASB, atribui-se a reduzida concentração de matéria orgânica em termos de DQO (característica específica do esgoto gerado no IFCE-LN) e, ainda, ao fato de a relação das frações de sólidos fixos e voláteis ter se apresentado próxima a 1, isto é, em termos comparativos, uma proporção de $50 \%$ para cada fração do total de sólidos afluente.

Todavia, é possível identificar uma melhoria dessa eficiência quando a retenção física de sólidos é melhorada no interior do reator (a partir de modificações na configuração básica do projeto).

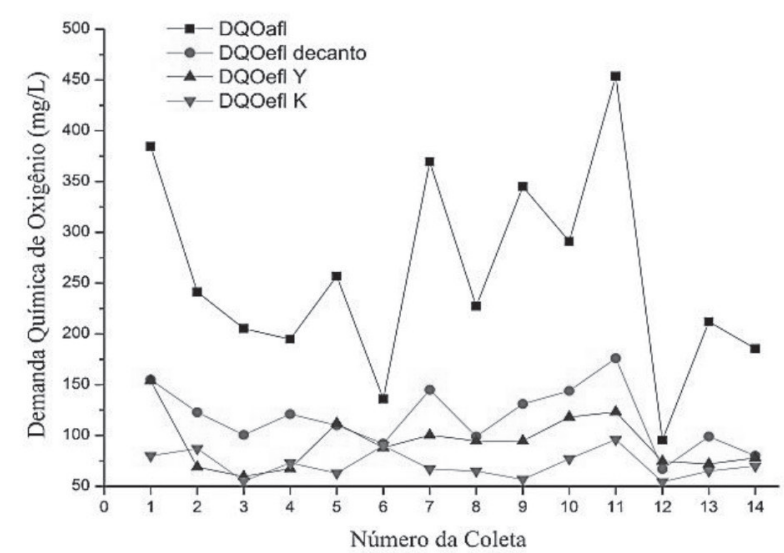

Figura 4: Perfil de remoção de DQO, em mg/L, nos 3 reatores estudados

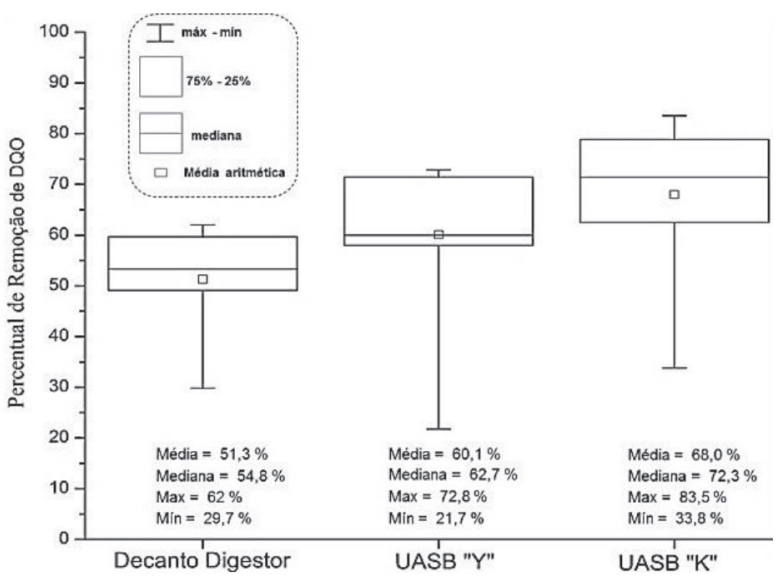

Figura 5: Distribuição do percentual de remoção de DQO nos 3 reatores estudados

Com relação à remoção de sólidos ou retenção destes dentro dos reatores, as Figuras 6 e 7 apresentam a remoção em mgSST/L e em percentual, respectivamente. Assim como na DQO afluente, é possível notar, na Figura 6, uma significativa variação da concentração de SST afluente, derivada principalmente das características da água residuária, como dito anteriormente.

Os percentuais de remoção (Figura 7) de SST mostraram-se satisfatórios para os dois reatores UASB (Y e K), com percentuais médios de $43,6 \%$ e $58,6 \%$, respectivamente. Essa tecnologia tem como uma de suas características a produção de gás e o consequente revolvimento do lodo de fundo, com sua ascensão e posterior queda dentro do reator. Esse processo tende a, em determinados momentos, desprender sólidos no efluente, o que pode acusar um incremento de DQO.

Segundo Chernicharo (2007), reatores UASB removem, em média, 40\% de sólidos afluentes, fato esse atingido pelos reatores operados, com destaque para o UASB K, que, por possuir um conjunto de 2 defletores de sólidos com separação de fases, apresentou-se 15\% mais eficiente do que o UASB Y na remoção dessa variável. A retenção de sólidos é importante não somente para assegurar uma menor carga orgânica efluente, mas também porque partículas sólidas podem abrigar patógenos, em especial, ovos de helmintos, o que caracteriza um risco sanitário quando da prática do reuso. 


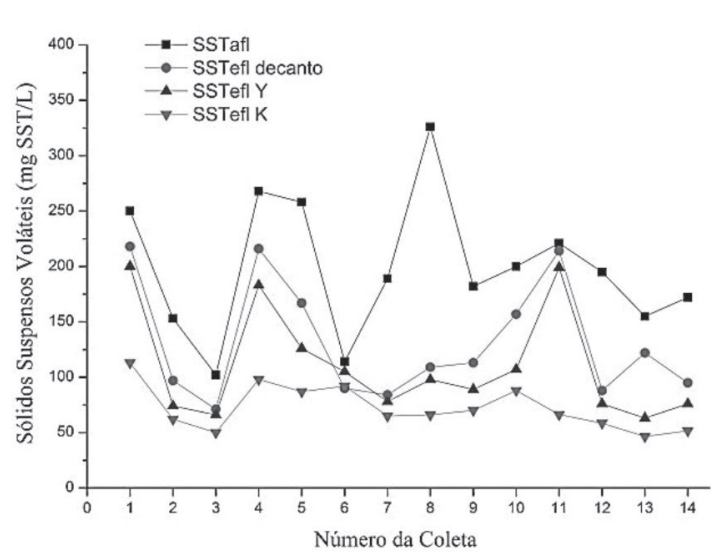

Figura 6: Perfil de remoção de SST, em mg SST/L, nos 3 reatores estudados

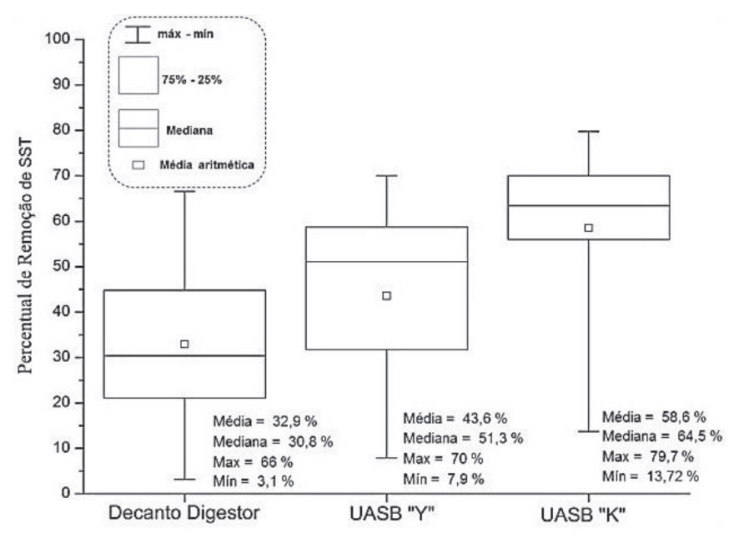

Figura 7: Distribuição do percentual de remoção de SST nos 3 reatores estudados

Ressalta-se que, mesmo com os percentuais médios de remoção de sólidos abaixo de $60 \%$, foi possível observar valores expressivos de retenção de ovos de helmintos nos 2 reatores UASB (Figuras 8 e 9), o que induz a uma não relação direta entre os sólidos suspensos totais e o os ovos de helmintos.

Na Figura 8, pode-se notar que, mesmo com um esgoto predominantemente doméstico, mas com uma maior população volátil (os alunos da instituição), foi detectada uma concentração elevada de ovos de helmintos, semelhante às características de esgotos sanitários (Von Sperling, 2011).

No aspecto "retenção de ovos de helmintos", foram obtidos percentuais médios de 32,9\% para o decanto digestor, 43,6 \% para o UASB Y e 58,6 \% para o UASB K. Esses valores, apesar de baixos em uma primeira análise, encontram-se de acordo com o estimado, pois, assim como para os sólidos, o fluxo hidráulico dos reatores UASB tende a ressuspender esses ovos de helmintos para a massa líquida novamente, facilitando sua saída no efluente.

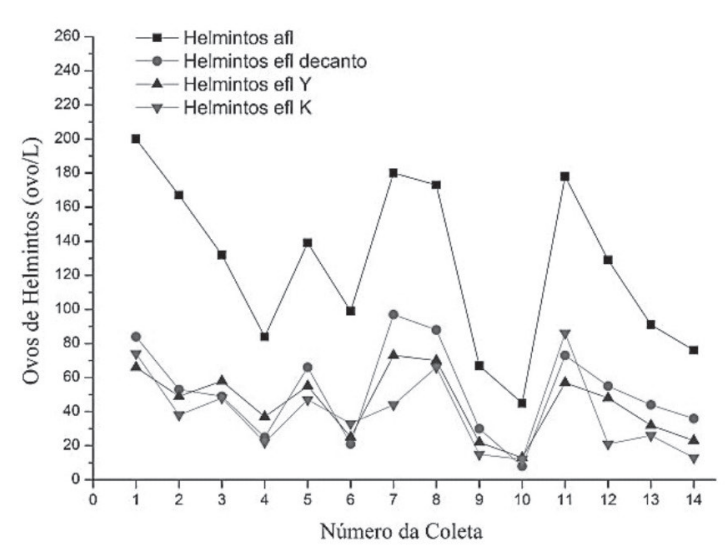

Figura 8: Perfil de remoção de Ovos de Helmintos, em ovos/L, nos 3 reatores estudados

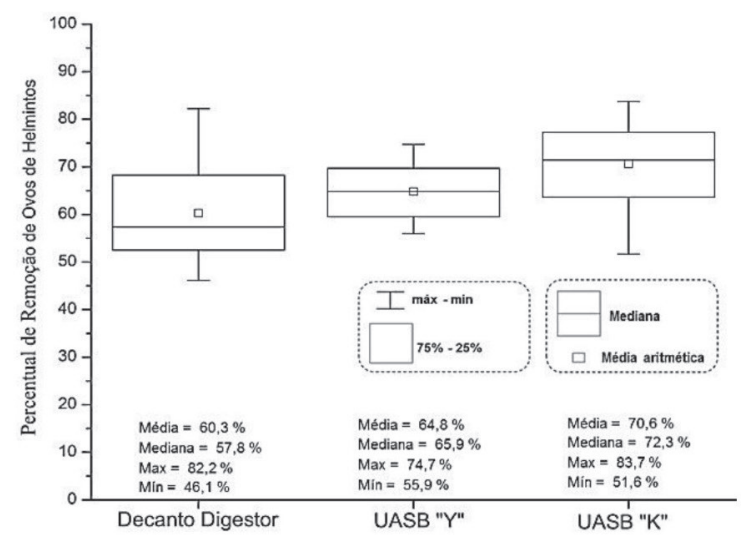

Figura 8: Distribuição do percentual de remoção de Ovos de Helmintos nos 3 reatores estudados

Nas Tabelas 5, 6 e 7, encontram-se dados estimados, calculados e/ou experimentais obtidos a partir da análise de viabilidade do reuso e da relação de custo-benefício em termos de materiais, equipamentos, condições de projeto ou operacionais e de manutenção dos sistemas estudados.

Os dados contidos nas tabelas citadas se tratam de projeções considerando alguns tipos de materiais, contudo, destaca-se que diversos outros podem ser utilizados, como: ferro fundido, aço, concreto ou materiais revestidos.

Após uma interpretação mais detalhada dos dados representados nas Tabelas 5, 6 e 7, percebe-se que o sistema UASB K, além de ter apresentado melhor remoção dos parâmetros avaliados, também se mostra mais atrativo no aspecto econômico, pois, de fato, se as etapas e condições fundamentais desde a escolha do material forem respeitadas e minuciosamente seguidas, pode-se obter um sistema sustentavelmente adequado. 
Essa afirmativa infere que se pode obter um sistema com garantia de boa qualidade do efluente tratado, possibilidade de desenvolvimento da prática de reuso aplicando um pós-tratamento simplificado para aplicações menos nobres, como também um pós-tratamento avançado, caso seja necessária uma ampliação mais significativa de fins e aplicabilidade do efluente pós-tratado pelo reator UASB, que, neste estudo, comprovou uma melhor efetividade com configuração melhorada na retenção de sólidos (reator UASB K).

Destaca-se que todos os aspectos considerados para a compilação dos dados de avaliação de custo-benefício foram pesquisados na literatura especializada e em levantamento prático de relatórios junto a algumas empresas de consultoria ambiental que fornecem sistemas pré-fabricados ao mercado. Dessa forma, valores podem variar, de acordo com marcas e fabricantes diferentes, mas não devem se afastar de forma considerável da faixa compreendida entre o valor mínimo e máximo para obtenção de cada tipo de sistema e tecnologia de tratamento estudada.

As estimativas referentes à mecanização, montagem e manutenção dos sistemas podem ser identificadas como variáveis, principalmente quando se avalia cada localidade a adotar o sistema de tratamento, visto que custos de terreno, material de construção, acesso aos caminhões limpa fossa e outros aspectos mais específicos podem alterar a estimativa de preço em grandes proporções quando se avalia a origem. Portanto, ao se considerar os reatores apresentados nesta pesquisa, sugestiona-se observar a região de estudo (Limoeiro do Norte, Ceará).

Tabela 5: Avaliação de custo-benefício referente ao decanto digestor com volume e vazão definidos para atendimento a uma família de 5 contribuintes, adotando uma contribuição per capita de esgoto de 100 L/hab.d.

\begin{tabular}{l|c|c|c|c|c}
\hline \multicolumn{7}{c}{ Decanto Digestor $\left(\boldsymbol{V}=\mathbf{1} \mathbf{m}^{3} / \boldsymbol{d} \boldsymbol{e} \boldsymbol{Q}=\mathbf{0 , 5} \mathbf{m}^{3} / \boldsymbol{d}\right)$} \\
\hline $\begin{array}{l}\text { Material } \\
\text { Utilizado }\end{array}$ & Mecanização & $\begin{array}{c}\text { Montagem / } \\
\text { Instalação }\end{array}$ & $\begin{array}{c}\text { Manutenção / Disposição } \\
\text { Final }\end{array}$ & Preço & $\begin{array}{c}\text { Eficiência Estimada ou } \\
\text { Experimental (\%) }\end{array}$ \\
\hline $\begin{array}{l}\text { Material simi- } \\
\text { lar ao PVC }\end{array}$ & Gravidade & In loco & $\begin{array}{c}\text { Limpa Fossa + Corpo } \\
\text { Hídrico Receptor }\end{array}$ & R $\$ 1.000$ & DQO $=51 ; \mathrm{SST}=33$ \\
\hline Polipropileno & $\begin{array}{c}\text { Bombeamento } \\
\text { Simples }\end{array}$ & Pré-Moldado & $\begin{array}{c}\text { Limpa Fossa + Valas de } \\
\text { Infiltração }\end{array}$ & $\mathrm{R} \$ 1.500$ & $\mathrm{DQO}=51 ; \mathrm{SST}=33$ \\
\hline Fibra de Vidro & $\begin{array}{c}\text { Conjunto } \\
\text { Motor-Bomba }\end{array}$ & Pré-Fabricado & Limpa Fossa + Sumidouro & $\mathrm{R} \$ 3.000$ & $\mathrm{DQO}=51 ; \mathrm{SST}=33$ \\
\hline
\end{tabular}

Tabela 6: Avaliação de custo-benefício referente ao reator UASB Y com volume e vazão definidos para atendimento a uma família de 5 contribuintes, adotando uma contribuição per capita de esgoto de 100 L/hab.d.

Reator $Y\left(V=0,32 \mathrm{~m}^{3}\right.$ e $\left.Q=0,5 \mathrm{~m}^{3} / \mathrm{d}\right)$

\begin{tabular}{l|c|c|c|c|c}
\hline $\begin{array}{l}\text { Material } \\
\text { Utilizado }\end{array}$ & Mecanização & $\begin{array}{c}\text { Montagem / } \\
\text { Instalação }\end{array}$ & $\begin{array}{c}\text { Manutenção/Disposição } \\
\text { Final }\end{array}$ & Preço & $\begin{array}{c}\text { Eficiência Estimada ou } \\
\text { Experimental (\%) }\end{array}$ \\
\hline PVC & Gravidade & In loco & $\begin{array}{c}\text { Limpa Fossa + Corpo } \\
\text { Hídrico Receptor }\end{array}$ & R \$ 600 & DQO $=60 ; \mathrm{SST}=44$ \\
\hline Polipropileno & $\begin{array}{c}\text { Bombeamento } \\
\text { Simples }\end{array}$ & Pré-Moldado & $\begin{array}{c}\text { Limpa Fossa + Valas de } \\
\text { Infiltração }\end{array}$ & $\mathrm{R} \$ 1.000$ & $\mathrm{DQO}=60 ; \mathrm{SST}=44$ \\
\hline Fibra de Vidro & $\begin{array}{c}\text { Conjunto } \\
\text { Motor-Bomba }\end{array}$ & Pré-Fabricado & Limpa Fossa + Sumidouro & $\mathrm{R} \$ 5.000$ & $\mathrm{DQO}=60 ; \mathrm{SST}=44$ \\
\hline
\end{tabular}

Tabela 7: Avaliação de custo-benefício referente ao reator UASB K com volume e vazão definidos para atendimento a uma família de 5 contribuintes, adotando uma contribuição per capita de esgoto de 100 L/hab.d.

\begin{tabular}{|c|c|c|c|c|c|}
\hline \multicolumn{6}{|c|}{ Reator $K\left(V=1 \mathrm{~m}^{3} / \mathrm{d}\right.$ e $\left.Q=0,64 \mathrm{~m}^{3} / \mathrm{d}\right)$} \\
\hline $\begin{array}{l}\text { Material } \\
\text { Utilizado }\end{array}$ & Mecanização & $\begin{array}{l}\text { Montagem/ } \\
\text { Instalação }\end{array}$ & $\begin{array}{l}\text { Manutenção / Disposição } \\
\text { Final }\end{array}$ & Preço & $\begin{array}{c}\text { Eficiência Estimada ou } \\
\text { Experimental (\%) }\end{array}$ \\
\hline PVC & Gravidade & In loco & $\begin{array}{c}\text { Limpa Fossa + Corpo } \\
\text { Hídrico Receptor }\end{array}$ & $\mathrm{R} \$ 800$ & $\mathrm{DQO}=68 ; \mathrm{SST}=59$ \\
\hline Polipropileno & $\begin{array}{l}\text { Bombeamento } \\
\text { Simples }\end{array}$ & Pré-Moldado & $\begin{array}{l}\text { Limpa Fossa + Valas de } \\
\text { Infiltração }\end{array}$ & $\mathrm{R} \$ 1.200$ & $\mathrm{DQO}=68 ; \mathrm{SST}=59$ \\
\hline Fibra de Vidro & $\begin{array}{c}\text { Conjunto } \\
\text { Motor-Bomba }\end{array}$ & Pré-Fabricado & Limpa Fossa + Sumidouro & $\mathrm{R} \$ 6.000$ & $\mathrm{DQO}=68 ; \mathrm{SST}=59$ \\
\hline
\end{tabular}


Acrescenta-se como vantagem dos reatores UASB sobre o decanto-digestor o fato de poder se dispensar a retirada periódica de lodo ou aumentar o período referente ao intervalo de limpeza, haja vista que ocorre a digestão do lodo sedimentado em taxas mais elevadas do que no decanto-digestor (Van Haandel et al., 1999; Coelho et al., 2001).

Nessas condições encontradas e avaliadas, é bastante factível o pós-tratamento desse efluente com vistas à prática do reuso, com um enfoque maior na retenção dos sólidos e ovos de helmintos restantes e remoção de coliformes. O nitrogênio remanescente, bem como o fósforo, não deve ser removido caso não prejudiquem as culturas previstas, pois se configuram como nutrientes para a maioria das culturas vegetais.

Mesmo sem a perspectiva de reuso, os sistemas UASB testados (com destaque para o sistema UASB K) mostraramse potencialmente capazes de atender às exigências ambientais para uma aplicação no saneamento rural ou como sistemas unifamiliares.

O decanto-digestor prevê em seu dimensionamento, de acordo com a NBR 7229 de 1993, o acréscimo compulsório imediato de $1 \mathrm{~m}^{3}$, independentemente da população contribuinte, o que torna o sistema mais oneroso em situações de pequenas contribuições e pouco acesso financeiro. Neste estudo, mesmo com volumes menores do que o decantodigestor, os reatores UASB responderam com uma margem de segurança operacional confiável (baixa amplitude nos parâmetros estudados no efluente tratado).

\section{Conclusão}

Os dados das análises preliminares da caracterização dos efluentes mostraram que, mesmo possuindo características distintas (doméstico e laboratorial), o esgoto predominantemente doméstico gerado no IFCE-LN mostrou-se adequado para o tratamento biológico proposto no projeto, bem como a implantação do sistema de reuso apresentou-se viável, visto que os benefícios referentes ao custo tanto econômico quanto ambiental mostraram-se favoráveis.

Após ter sido desenvolvida esta pesquisa no âmbito do tema proposto, pode-se perceber que os sistemas foram operados sob as expectativas do projeto, tanto em termos de retenção de sólidos como em remoção de material orgânico. Portanto, pode-se dizer que o novo modelo (UASB K) também é uma boa alternativa de tratamento para pequenas vazões, inclusive tendo superado o reator $\mathrm{Y}$ em termos de percentuais de remoção da matéria orgânica (acréscimo de 8\% em relação ao Y) e sólidos (acréscimo de 15\%). Ressalta-se que ambos foram consideravelmente mais eficientes na remoção dos parâmetros avaliados quando comparados ao decanto-digestor.

Diante da viabilidade econômica e ambiental do reuso proposto dentro do IFCE-LN, destacando-se a importância da boa escolha da constituição do sistema ainda em fase de projeto, pode-se observar, através de análises laboratoriais (em especial, quantificação em ovos de helmintos), a qualidade da água produzida, visto que o aspecto microbiológico é fundamental para a efetivação da prática do reuso. Destaca-se que o sistema deve sofrer um pós-tratamento, mesmo que apenas composto de desinfecção, para efetivar o processo de implantação da técnica de reuso de forma segura.

Apesar de os dados terem sido obtidos em vazões reduzidas (escala de teste), percebeu-se que, ao realizar a projeção para maiores contribuições, os sistemas ainda se mantinham dentro de uma realidade possível, sobretudo econômica, ao atendimento unifamiliar e na abrangência até pequenas comunidades.

Além disso, o efluente tratado é composto de uma concentração considerável de nutrientes e matéria orgânica em baixas concentrações. Espera-se que essa prática seja realizada não só no campus de Limoeiro do Norte, mas que seja fator motivador para a continuação de pesquisas na área. A efetivação em outras instituições contribuirá para a melhoria ambiental e social, abrindo caminhos à prática do reuso, um tema ainda recente, muito importante e essencial para a preservação e conservação dos recursos hídricos, principalmente na região semiárida, que sofre com problemas de escassez.

\section{Referências}

ASSOCIAÇÃO BRASILEIRA DE NORMAS TÉCNICAS. NBR 7229: projeto, construção e operação de sistemas de tanques sépticos. Rio de Janeiro, 1993.

AMERICAN PUBLIC HEALTH ASSOCIATION. Standard methods for the examination of water and wastewater. $21^{\text {st }}$. ed. Washington, DC, 2005. 
ANDRADE NETO, C. O.; VAN HAANDEL, A. C.; MELO, H. N. S. O Uso do filtro anaeróbio para pós-tratamento de efluentes de reatores anaeróbios no Brasil. In: X SIMPÓSIO LUSO-BRASILEIRO DE ENGENHARIA SANITÁRIA E AMBIENTAL, 10., 2002, Braga, Portugal. Anais... Braga: APESB/APRH/ABES, 2002. CD-ROM.

CONSELHO NACIONAL DO MEIO AMBIENTE. Resolução №357 de 17 de março de 2005. Classificação das águas doces, salobras e salinas do território nacional. Diário Oficial da União, Brasília, DF, Seção 1, p. 58-63, 18 de mar. 2005.

CONSELHO NACIONAL DO MEIO AMBIENTE. Resolução No430 de 13 de maio de 2011. Dispõe sobre as condições e padrões de lançamento de efluentes, complementa e altera a Resolução № 357, de 17 de março de 2005, do Conselho Nacional do Meio Ambiente-CONAMA. Diário Oficial da União, Brasília, DF, Nº 92, p. 89, 16 maio. 2011.

BUCHAUER K. A comparison of two simple titration procedures to determine volatile fatty acids in effluents to wastewater and sludge treatment processes. Water SA, v. 24, n. 1, p. 49-56, 1998.

CEARÁ. Superintendência Estadual do Meio Ambiente. Portaria Nº154 de 22 de julho de 2002. Dispõe sobre padrões e condições para lançamento de efluentes líquidos gerados por fontes poluidoras. Diário Oficial do Estado do Ceará, Fortaleza, Caderno Único, p. 32-33, 1 de out. 2002.

CHERNICHARO, C. A. L. Princípios do tratamento biológico de águas residuárias. Belo Horizonte: UFMG, 2007. v. 5. COELHO, A. L. S. S. et al. Estudo comparativo entre sistemas de tratamento unifamiliar de esgoto com pós $\square$ tratamento. In: CONGRESSO BRASILEIRO DE ENGENHARIA SANITÁRIA E AMBIENTAL, 21., 2001, João Pessoa. Anais... João Pessoa: ABES, p 5-9, 2001.

COELHO, A. L. S. S. et al. The UASB reactor as an alternative for the septic tank for on-site sewage treatment. In: SPECIALIZED CONFERENCE ON SMALL WATER AND WASTE WATER TREATMENT SYSTEMS, 5., 2002, Istanbul. Proceedings... Istanbul, 2002. p 659-665.

COELHO, A. L. S. S. et al. The UASB reactor as an alternative for the septic tank for on-site sewage treatment. Wat. Sci. Techn., v. 48, n.12, p 221-226, 2003.

INSTITUTO BRASILEIRO DE GEOGRAFIA E ESTATÍSTICA. Pesquisa nacional de saneamento básico 1989/2000. Disponível em: < http://educacao.uol.com.br/geografia/saneamento-basico.jhtm>. Acesso em: 22 nov. 2011.

JORDÃO, E. P.; PESSOA, C. Tratamento de esgoto doméstico. 6. ed. Rio de Janeiro: ABES, 2011.

METCALF \& EDDY. Wastewater engineering: treatment, disposal, reuse. 4. ed. New York: McGraw-Hill, 2003. p. 765-926.

VAN HAANDEL, A.; LETTINGA, G. Tratamento anaeróbio de esgotos: um manual para regiões de clima quente. Campina Grande, PB: Epgraf, 1994.

VAN HAANDEL, A. C.; MARAIS, G. V. R. O comportamento do sistema de lodo ativado: teoria e aplicações para projeto e operação. Campina Grande: Epgraf, 1999. p. 472.

VAN HAANDEL, A. C.; CAVALCANTI, P. F. F.; SOUSA, F. P. Efeito da proporção área/profundidade sobre o desempenho de um reator UASB. In: CONGRESSO BRASILEIRO DE ENGENHARIA SANITÁRIA E AMBIENTAL, 20., 1999. Rio de Janeiro. Anais... Rio de Janeiro: ABES, p. 939-948. 1999.

VAN HAANDEL, A. C. et al. Estratégia de descarga do lodo de excesso de reatores UASB tratando esgoto municipal. In: CONGRESSO BRASILEIRO DE ENGENHARIA SANITÁRIA E AMBIENTAL, 20, Anais... Rio de Janeiro: ABES. p. 949-962. 1999.

VON SPERLING, M. Introdução à qualidade das águas e ao tratamento de esgotos. Belo Horizonte: UFMG, 2011. p. 452 . 
Sobre os autores

\section{Bruna Gomes de Lima}

Graduanda em Tecnologia em Saneamento Ambiental pelo Instituto Federal de Educação Ciência e Tecnologia - IFCE, campus Limoeiro do Norte. Bolsista de Iniciação Científica PIBITI/CNPq. Analista do Laboratório de Controle Ambiental LCA do IFCE, campus Limoeiro do Norte.

\section{Francisca Socorro Peixoto}

Graduanda em Tecnologia em Saneamento Ambiental pelo Instituto Federal de Educação Ciência e Tecnologia - IFCE, campus Limoeiro do Norte. Bolsista de Iniciação Científica PIBITI/CNPq. Analista do Laboratório de Controle Ambiental (LCA) do IFCE, campus Limoeiro do Norte.

\section{Heraldo Antunes Silva Filho}

Tecnólogo em Gestão Ambiental pelo Instituto Federal de Educação Ciência e Tecnologia - IFCE (2003-2006). Mestre em Engenharia Civil e Ambiental - Área de Concentração em Engenharia Sanitária (UFCG - 2007-2009). Professor do IFCE, campus Limoeiro do Norte. Coordenador do Laboratório de Controle Ambiental - LCA do IFCE, campus Limoeiro do Norte.

\section{Elivânia Vasconcelos Moraes dos Santos}

Tecnóloga em Gestão Ambiental pelo Instituto Federal de Educação Ciência e Tecnologia - IFCE (2003-2006). Mestre em Engenharia Civil e Ambiental - Área de Concentração em Engenharia Sanitária (UFCG - 2007-2009). Professora do IFCE, campus Limoeiro do Norte. Coordenadora do Centro Experimental de Tratamento de Esgotos - CETE do IFCE, campus Limoeiro do Norte. 